\title{
Coupled mother-child model for bioaccumulation of POPs in nursing infants
}

\author{
Trapp, Stefan; Bomholtz, L.M.; Legind, Charlotte Nielsen
}

Published in:

Environmental Pollution

Link to article, DOI:

10.1016/j.envpol.2007.12.036

Publication date:

2008

Link back to DTU Orbit

Citation (APA):

Trapp, S., Bomholtz, L. M., \& Legind, C. N. (2008). Coupled mother-child model for bioaccumulation of POPs in nursing infants. Environmental Pollution, 156(1), 90-98. https://doi.org/10.1016/j.envpol.2007.12.036

\section{General rights}

Copyright and moral rights for the publications made accessible in the public portal are retained by the authors and/or other copyright owners and it is a condition of accessing publications that users recognise and abide by the legal requirements associated with these rights.

- Users may download and print one copy of any publication from the public portal for the purpose of private study or research.

- You may not further distribute the material or use it for any profit-making activity or commercial gain

- You may freely distribute the URL identifying the publication in the public portal

If you believe that this document breaches copyright please contact us providing details, and we will remove access to the work immediately and investigate your claim. 
1 Environmental Pollution 2008, 156, 90-98

\section{Coupled Mother-Child Model for Bioaccumulation of POPs in Nursing}

\section{Infants}

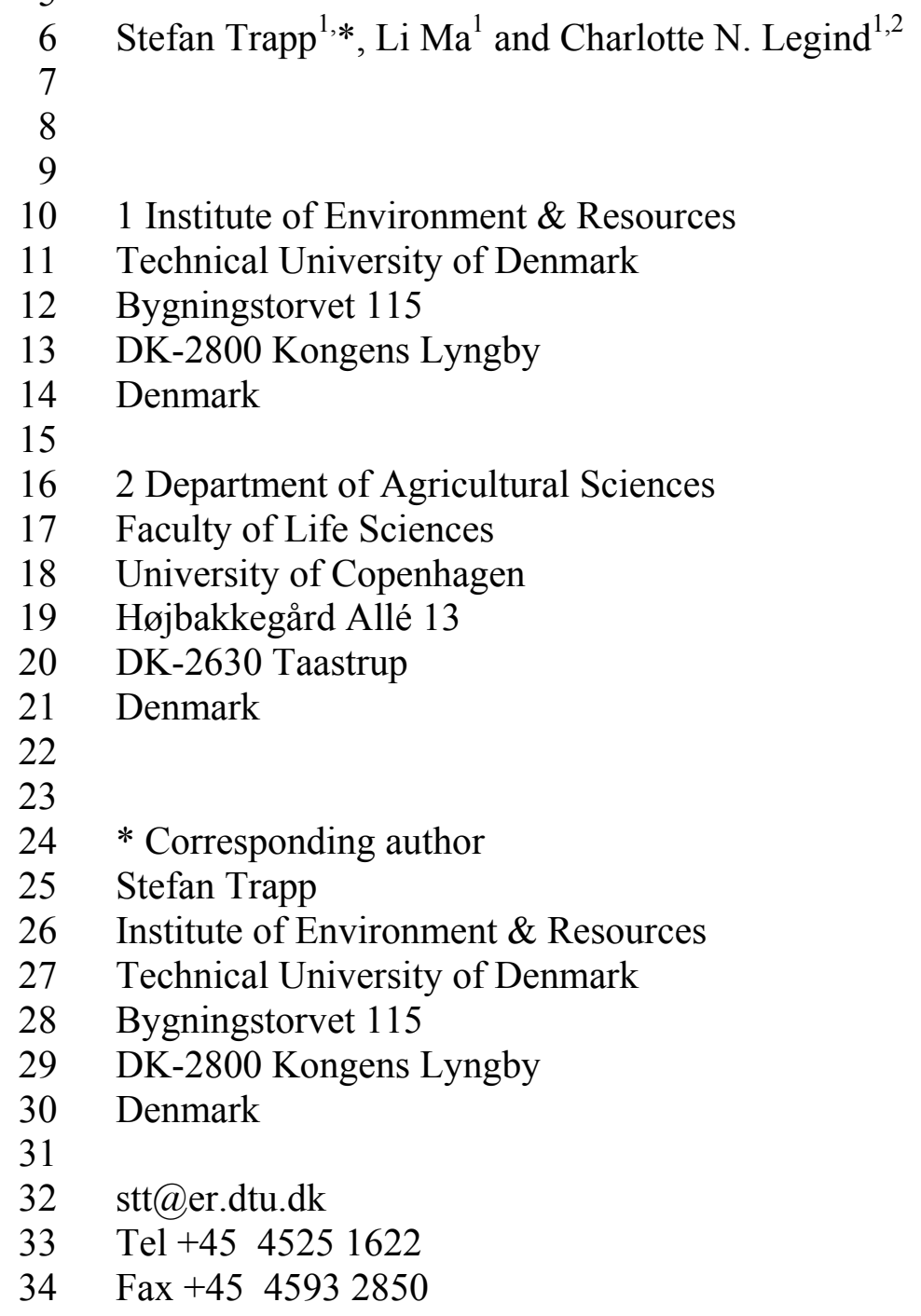


36 Capsule: This paper addresses a model for accumulation of organic compounds by

37 mother and breast-fed infant, applicable for exposure assessment within larger

38 frameworks.

41 Abstract

43 Bioaccumulation of persistent organic pollutants (POPs) leads to high levels in human

44 milk and high doses of POPs for nursing infants. This is currently not considered in

45 chemical risk assessment. A coupled model for bioaccumulation of organic chemicals in

46 breastfeeding mother and nursing infant was developed and tested for a series of organic

47 compounds. The bioaccumulation factors (BAF) in mother, breast milk and child were

48 predicted to vary with $\log$ Kow and, for volatile compounds, with Kaw and concentration

49 in air. The concentrations of POPs in the infant body increase the first half year to about

50 factor 3 above mother and decline thereafter to lower levels. The predicted results are

51 close to empirical data and to an empirical regression. The new mother-child model is

52 compact due to its easy structure and the analytical matrix solution. It could be added to

53 existing exposure and risk assessment systems, such as EUSES.

58 Keywords: Accumulation; Breast milk; Human exposure; Infant; Model; POP 


\section{Introduction}

60

61 Persistent organic pollutants (POPs) are "chemicals that remain intact in the environment

62 for long periods, become widely distributed geographically, accumulate in the fatty tissue

63 of living organisms, and are toxic to humans and wildlife" (UNEP 2007). POPs, such as

64 polychlorinated dibenzodioxins and -furans (PCDD/F), polychlorinated biphenyls (PCB)

65 and chloroorganic pesticides, have been detected in human milk samples all over the

66 world (Rogan et al. 1986, Schecter et al. 1996, Filser et al. 1997, Raab et al. 2007, Shen

67 et al. 2007, Wittsiepe et al. 2007, Tanabe and Kunisue 2007). This raised considerable

68 concern about adverse health effects on nursing infants (Harrison 2001, CEHAPE 2004,

69 US EPA 2006).

71 The uptake of POPs, such as PCDD/F, by adults is mainly via food ingestion (Travis and

72 Hattemeyer-Frey 1991). The uptake by nursing infants via breast milk has been reported

73 to be higher than by adults via diet, for some POPs at levels above the acceptable daily

74 intake (Dahl et al. 1995, Kreuzer et al. 1997, Schade and Heinzow 1998, BGVV 2000,

75 Tanabe and Kunisue 2007). POPs may accumulate for a longer period in the body of the

76 mother and then be transferred to the nursing infant via mother's milk. Travis et al. (1988)

77 developed empirical relations for the accumulation of chemicals in human adipose tissue

78 and human milk. The regressions are based on 12 (tissue) or 6 (milk) organic chemicals

79 with a $\log K_{\text {OW }}$ between 1.32 and 6.50 (tissue) or 5.16 to 6.50 (milk). The

80 bioaccumulation factors $\mathrm{B}_{\mathrm{f}}($ tissue $)$ and $\mathrm{B}_{\mathrm{m}}(\mathrm{milk})$ were defined as 
91 Travis et al. (1988) related these bioaccumulation factors to the log $K_{O W}$ of the

92 substances.

$94 \quad \mathrm{~B}_{\mathrm{f}}=2.0 \times 10^{-4} \mathrm{Kow}^{1.05}$ $\left[\frac{d}{k g}\right] \quad(\mathrm{n}=12, \mathrm{r}=0.98)$

$95 \quad \mathrm{~B}_{\mathrm{m}}=9.8 \times 10^{-5} \mathrm{Kow}^{1.14}$ $\left[\frac{d}{k g}\right] \quad(\mathrm{n}=6, \mathrm{r}=0.97)$

97 Besides this empirical approach, several mathematical model approaches exist to predict

98 human tissue concentrations after uptake, e.g. the models prepared by Kreuzer et al.

99 (1997) or Filser et al. (1997) and Maruyama et al. (2003) for PCDD/F. Accumulation in

100 the food chain with subsequent accumulation in humans was addressed by Czub and

101 McLachlan (2004a,b). To summarize, compound-specific models, comprehensive

102 numerical models and also easy empirical models for the prediction of the accumulation 103 of POPs in humans are available.

105 However, what lacks is a model predicting accumulation of POPs or other compounds in

106 breastfeeding mother and nursing infant after uptake of chemicals via diet or other 107 relevant sources by mother, which is compact enough to be combined with other models 
108 and estimation routines, e.g., for chemical safety assessment tools such as EUSES (EC

109 1996).

110

111 "Traditional risk assessment approaches and environmental health policies have focused

112 mainly on adults and adult exposure patterns, utilizing data from adult humans or adult

113 animals" (CEHAPE 2004). Indeed, current chemical risk assessment in the EU (EC 2003)

114 considers only grown-ups (70 kg bodyweight). An additional focus on children and in

115 particular nursing infants, which are one trophic level higher and are eventually also more

116 sensitive to chemicals, requires a compact exposure estimation method that can run with

117 a minimum data set.

118

119 This paper addresses the development, parameterization, sensitivity analysis, validation

120 and application of a coupled model for accumulation of organic compounds by nursing

121 mother and child. The coupled differential equations were solved analytically. The model

122 was tested with $2,3,7,8$-TCDD and compared to empirical data for 11 other compounds

123 collected by Travis et al. (1988). 


\section{$124 \quad 2$ Methods}

\section{$126 \quad 2.1$ Model Development}

127 Figure 1 gives an overview of the system considered by the model. The human body is

128 considered as a flux-through system. The input of chemical occurs via diet (mother) or

129 milk (child) and inhalation (both). Inside the body, phase equilibrium is assumed. The

130 compound is eliminated from the body by exhalation and excretion (both together are

131 named "outflux"), by metabolism and, in case of the nursing mother, with breast milk.

$133<$ Figure 1>

\section{Mother before birth of the child}

136 The input of chemical into the mother is independent of the concentration in her body,

$137 C_{H}$, while the output is proportionally related to it. This yields a linear differential

138 equation for the mass balance of the form

139

$140 \quad \frac{d m}{d t}=I-k \times m$

142 where $m[\mathrm{mg}]$ is the mass of chemical in the human body, $I\left[\mathrm{mg} \mathrm{d}^{-1}\right]$ is the sum of daily

143 uptake of chemical and $k\left[\mathrm{~d}^{-1}\right]$ is the loss rate constant.

145 The input $I$ can be derived from measurements or exposure assessments. The loss rate 146 constant $k$ is calculated from the flux of chemical out of the body. 
148 The human body is considered as composed of the phases lipids and water. Lipids were

149 assumed to dissolve the chemical similar to octanol. The phase equilibrium between

150 concentration in human body, $C_{H}\left[\mathrm{mg} \mathrm{kg}^{-1}\right]$, and concentration in water, $C_{W}\left[\mathrm{mg} \mathrm{L}^{-1}\right]$, is

$152 \quad K_{H W}=\frac{C_{H}}{C_{W}}=W_{H}+\frac{L_{H}}{\rho_{L}} \times K_{O W} \quad\left[\frac{L}{k g}\right]$

154 where $K_{H W}$ is the partition coefficient human body to water $\left[\mathrm{L} \mathrm{kg}^{-1}\right], W_{H}$ is the water

155 content $\left[\mathrm{L} \mathrm{kg}^{-1}\right]$ and $L_{H}$ is the lipid content of the human body $\left[\mathrm{kg} \mathrm{kg}^{-1}\right], \rho_{L}$ is the density

156 of lipids $\left[\mathrm{kg} \mathrm{L}^{-1}\right]$ and $K_{O W}\left[\mathrm{~L} \mathrm{~L}^{-1}\right]$ is the partition coefficient between octanol and water.

158 The change of chemical mass in time due to outflux of chemical from the body $d m_{F} / d t$

$159\left[\mathrm{mg} \mathrm{d}^{-1}\right]$ is the sum of outflux with water, lipid and air

$\frac{d m_{F}}{d t}=F_{W} \times C_{F, W}+F_{L} \times C_{F, L}+F_{A} \times C_{F, A}=F \times C_{F}$

$\left[\frac{m g}{d}\right]$

162

163 where $F_{W}$ is the outflux of water $\left[\mathrm{L} \mathrm{d}^{-1}\right], F_{L}$ is the outflux of lipids $\left[\mathrm{kg} \mathrm{d}^{-1}\right]$ (with feces)

164 and $F_{A}$ is the outflux of air $\left[\mathrm{L} \mathrm{d}^{-1}\right]$ (exhalation). $C_{F, W}\left[\mathrm{mg} \mathrm{L}^{-1}\right], C_{F, L}\left[\mathrm{mg} \mathrm{kg}^{-1}\right]$ and $C_{F, A}[\mathrm{mg}$

$\left.165 \mathrm{~L}^{-1}\right]$ are the concentrations in the water, lipid and gas fraction of the outflux; $C_{F}\left[\mathrm{mg} \mathrm{kg}^{-1}\right]$

166 is the weighted average concentration in the outflux. The total material outflux $F\left[\mathrm{~kg} \mathrm{~d}^{-1}\right]$

167 is the sum of the outfluxes of water, lipids and air, 
$169 \quad F=F_{W} \times \rho_{W}+F_{L}+F_{A} \times \rho_{A} \quad\left[\frac{k g}{d}\right]$

170

171 Using the assumption of phase equilibrium we can rewrite to

172

$173 F \times C_{F}=F \times f_{W} \times C_{F, W}+F \times f_{L} \times K_{O W} \times C_{F, W}+F \times f_{A} \times K_{A W} \times C_{F, W}$

174

175 where $K_{A W}$ is the partition coefficient $\left[\mathrm{L} \mathrm{L}^{-1}\right]$ between air and water (also known as

176 dimensionless Henry's Law constant), and $f$ are the flux fractions [L/d : kg/d] of water W,

177 lipids L and air A of the total flux F,

178

$179 f_{W}=\frac{F_{W}}{F}, f_{L}=\frac{F_{L} / \rho_{L}}{F}$ and $f_{A}=\frac{F_{A}}{F} \quad\left[\frac{L}{k g}\right]$

180

181 The average concentration of chemical in the outflux, $C_{F}$, is then

182

183

$$
C_{F}=f_{W} \times C_{F, W}+f_{L} \times K_{O W} \times C_{F, W}+f_{A} \times K_{A W} \times C_{F, W}
$$

185 Note that for phase equilibrium, $C_{F, W}$ (concentration in aqueous phase of outflux) equals

$186 C_{W}$ (concentration in aqueous phase of human body), and thus we derive

$188 K_{F W}=\frac{C_{F}}{C_{W}}=f_{W}+f_{L} \times K_{O W}+f_{A} \times K_{A W} \quad\left[\frac{L}{k g}\right]$ 
190 where $K_{F W}\left[\mathrm{~L} \mathrm{~kg}^{-1}\right]$ is the partition coefficient between outflux $\left[\mathrm{kg} \mathrm{d}^{-1}\right]$ and water $\left[\mathrm{L} \mathrm{d}^{-1}\right]$.

191 Then, the partition coefficient between human body and outflux, $K_{H F}[\mathrm{~kg} / \mathrm{kg}]$, is

192

$193 \quad K_{H F}=\frac{C_{H}}{C_{F}}=\frac{K_{H W}}{K_{F W}} \quad\left[\frac{\mathrm{kg}}{\mathrm{kg}}\right]$

195 where $C_{H}$ and $C_{F}$ are the concentrations $\left[\mathrm{mg} \mathrm{kg}^{-1}\right]$ in human body and outflux in phase

196 equilibrium. It follows for the loss rate constant $k\left[\mathrm{~d}^{-1}\right]$ in eq. 1 , which is the sum of the

197 losses by outflux and by metabolism or degradation with first-order $k_{\text {deg }}\left[\mathrm{d}^{-1}\right]$

198

$199 \quad k=\frac{F}{M_{H} \times K_{H F}}+k_{\mathrm{deg}} \quad\left[\frac{1}{d}\right]$

201 where $M_{H}[\mathrm{~kg}]$ is the bodyweight. The analytical solution of equation (1) for the chemical

202 mass $m[\mathrm{mg}]$ in human body at time $t$ is

203

$204 \quad m(t)=m_{0} \times e^{-k t}+\frac{I}{k}\left(1-e^{-k t}\right)$

206 which gives in steady-state $(t \rightarrow \infty)$

207

$208 \quad m(\infty)=\frac{I}{k}$ 
210 Concentrations $C_{H}[\mathrm{mg} / \mathrm{kg}]$ in the human body were derived from $C_{H}=m / M_{H}$, assuming a

211 constant bodyweight $M_{H}$

212

213

$$
C_{H}(\infty)=\frac{m(\infty)}{M_{H}}=\frac{I}{k \times M_{H}} \quad\left[\frac{m g}{k g}\right]
$$

215 This solution was used to calculate the concentration of chemical in the woman before

216 birth of the child (and before pregnancy, the bodyweight is constant at $60 \mathrm{~kg}$ ).

\section{Nursing mother with child}

219 In this scenario, the mother gives birth to a child and nurses the infant. Equations for the

220 mother were modified, and new equations for breast milk and nursing child were

221 introduced.

223 Mother. Nursing changes the outflux from the mother. Milk consists in the model of

224 water and lipids. The flux of milk $F_{M}\left[\mathrm{~kg} \mathrm{~d}^{-1}\right]$ was added to the outflux $F$ in equation (4)

$$
F=F_{W} \times \rho_{W}+F_{L}+F_{A} \times \rho_{A}+W_{M} \times \rho_{W} \times F_{M}+L_{M} \times F_{M} \quad\left[\frac{k g}{d}\right]
$$

228 where $W_{M}\left[\mathrm{~L} \mathrm{~kg}^{-1}\right]$ is the water content and $L_{M}\left[\mathrm{~kg} \mathrm{~kg}^{-1}\right]$ is the lipid content of human

229 milk. Fractions of outflux $\left[\mathrm{L} \mathrm{kg}^{-1}\right] f_{W}, f_{L}$ and $f_{A}$ were recalculated for the case of nursing. 
$231 f_{W}=\frac{F_{W}+W_{M} \times F_{M}}{F}, f_{L}=\frac{F_{L}+L_{M} \times F_{M}}{F \times \rho_{L}}$ and $f_{A}=\frac{F_{A}}{F} \quad\left[\frac{L}{k g}\right]$

233 The other equations (eqs. 1,2, 8-13) were applied without changes, but the new values of

$234 \quad F$ and $f$ were entered.

235

236 Milk. With breast milk, chemical is lost from the mother and transferred to the baby

237 (Schecter et al. 1996). To calculate the concentration of chemical in milk, phase

238 equilibrium between milk and mother was assumed. The concentration in milk $C_{M}[\mathrm{mg}$ $\left.239 \mathrm{~kg}^{-1}\right]$ is

$$
C_{M}=K_{M H} \times C_{H} \quad\left[\frac{m g}{k g}\right]
$$

243 where $K_{M H}\left[\mathrm{~kg} \mathrm{~kg}^{-1}\right]$ is the partition coefficient between milk and human. The partition

244 coefficient milk to water $K_{M W}\left[\mathrm{~L} \mathrm{~kg}^{-1}\right]$ is

$246 \quad K_{M W}=\frac{C_{M}}{C_{W}}=W_{M}+\frac{L_{M}}{\rho_{L}} \times K_{O W} \quad\left[\frac{L}{k g}\right]$

248 The partition coefficient between milk and human body $K_{M H}[\mathrm{~kg} / \mathrm{kg}]$ is then

249

$250 \quad K_{M H}=\frac{C_{M}}{C_{H}}=\frac{K_{M W}}{K_{H W}}$

$\left\lceil\frac{k g}{k g}\right]$ 
252 Child. The breast-fed infant can take up chemicals by breast milk and by inhalation.

253 Breathing is external input to the child, $I_{C}=F_{A} \times C_{A}$, where $F_{A}$ [here: $\mathrm{m}^{3} \mathrm{~d}^{-1}$ ] is the flux

254 of inhaled air and $C_{A}\left[\mathrm{mg} \mathrm{m}^{-3}\right]$ is the concentration of chemical in air. Loss of chemical

255 occurs via outflux and by metabolic elimination with first-order rate constant $k_{d e g}\left[\mathrm{~d}^{-1}\right]$.

256 The mass balance for the child is

257

$258 \quad \frac{d m_{C}}{d t}=I_{C}+C_{M} \times F_{M}-C_{F} \times F_{C}-k_{\mathrm{deg}} \times m_{C}$

260 where $C_{M}\left[\mathrm{mg} \mathrm{kg}^{-1}\right]$ denotes the concentration in breast milk, $F_{M}\left[\mathrm{~kg} \mathrm{~d}^{-1}\right]$ is the flux of

261 milk from mother to child, $C_{F}\left[\mathrm{mg} \mathrm{kg}^{-1}\right]$ is the concentration in the outflux of the child

262 and $F_{C}\left[\mathrm{~kg} \mathrm{~d}^{-1}\right]$ is the outflux from the child.

263

264 Using the partition coefficients, the equation can be rewritten to

$266 \frac{d m_{C}}{d t}=I_{C}+K_{M H} \frac{F_{M}}{M_{H}} \times m_{H}-\frac{F_{C}}{K_{C F} \times M_{C}} \times m_{C}-k_{\operatorname{deg}} \times m_{C} \quad\left[\frac{m g}{d}\right]$

268 where $m_{H}[\mathrm{mg}]$ is the chemical mass in mother (human $\mathrm{H}$ ), $m_{C}[\mathrm{mg}]$ is the chemical mass

269 in the child, $K_{C F}\left[\mathrm{~kg} \mathrm{~kg}^{-1}\right]$ is the partition coefficient between child and outflux and $M_{C}$

$270[\mathrm{~kg}]$ is the body mass of the child. The phase equilibrium between child body (index C)

271 and water (index W) is

272 
$273 \quad K_{C W}=\frac{C_{C}}{C_{W}}=W_{C}+\frac{L_{C}}{\rho_{L}} \times K_{O W} \quad\left[\frac{L}{k g}\right]$

275 where $K_{C W}\left[\mathrm{~L} \mathrm{~kg}^{-1}\right]$ is the partition coefficient child body to water, $C$ is the equilibrium

276 concentration in child, index $C\left[\mathrm{mg} \mathrm{kg}^{-1}\right]$, or water, index $\mathrm{W}\left[\mathrm{mg} \mathrm{L}^{-1}\right], W_{C}\left[\mathrm{~L} \mathrm{~kg}^{-1}\right]$ is the

277 water content and $L_{C}\left[\mathrm{~kg} \mathrm{~kg}^{-1}\right]$ is the lipid content of the child body. The initial

278 concentration in the child $C_{C}(0)\left[\mathrm{mg} \mathrm{kg}^{-1}\right]$ was calculated from phase equilibrium to

279 mother

280

$281 \quad C_{C}(0)=\frac{K_{C W}}{K_{H W}} \times C_{H}$

283 The outflux $F_{C}\left[\mathrm{~kg} \mathrm{~d}^{-1}\right]$ from the child was summed up, as was done for the outflux from 284 the mother:

$$
F_{C}=F_{W} \times \rho_{W}+F_{L}+F_{A} \times \rho_{A}
$$

288 where indeces W, L and A indicate water, lipid and air. Again, the flux fractions were

289 used to calculate the phase equilibrium between outflux and water, $K_{F W}$ :

$$
K_{F W}=\frac{C_{F}}{C_{W}}=f_{W}+f_{L} \times K_{O W}+f_{A} \times K_{A W} \quad\left[\frac{L}{k g}\right]
$$

293 The partition coefficient between child body and outflux, $K_{C F}[\mathrm{~kg} / \mathrm{kg}]$, is 
$295 \quad K_{C F}=\frac{C_{C}}{C_{F}}=\frac{K_{C W}}{K_{F W}} \quad\left[\frac{\mathrm{kg}}{\mathrm{kg}}\right]$

\section{$297 \quad 2.2$ Matrix Solution}

298 The differential equations of mother and child are coupled and were treated as a linear

$2992 \times 2$ matrix system of the form

300

$301 \quad \frac{d m_{1}}{d t}=a_{11} m_{1}+a_{12} m_{2}+I_{1}$

$302 \quad \frac{d m_{2}}{d t}=a_{21} m_{1}+a_{22} m_{2}+I_{2}$

304 Matrix element 1 is the mother. The matrix constant $a_{11}\left[\mathrm{~d}^{-1}\right]$ is the sum of all loss

305 processes from the mother and is identical with the negative loss rate $k$ (eq. 10). The

306 matrix constant $a_{12}\left[\mathrm{~d}^{-1}\right]$ is what mother receives from the child and is zero (therefore, the

307 equation for chemical mass in mother can be solved independently of that for the child,

308 eqs. 1 and 11$)$. Input $I_{1}\left[\mathrm{mg} \mathrm{d}^{-1}\right]$ is the sum of all input to mother.

310 Matrix element 2 is the nursed child. The matrix constant $a_{21}\left[\mathrm{~d}^{-1}\right]$ describes the transfer

311 via milk from mother to child, $a_{21}=K_{M H} \times F_{M} / M_{H}$. The matrix constant $a_{22}\left[\mathrm{~d}^{-1}\right]$ describes

312 all losses of chemical from the child, $a_{22}=-F_{C} /\left(K_{C F} \times M_{C}\right)-k_{\text {deg }}$. Input $I_{2}$ includes all

313 chemical input independent from the mother, i.e. via inhalation, $I_{2}=F_{A} \times C_{A}$. A standard

314 solution for this system of differential equations exists for the case of constant rates and 
315 inputs (Nazaroff and Alvarez-Cohen 2001). Concentrations [mg/kg] were derived by

316 dividing the chemical mass $[\mathrm{mg}]$ by the bodyweight $[\mathrm{kg}]$.

\section{$318 \quad 2.3$ Parameterization of the Model}

319 Input data (Table 1) was selected from several sources, preferably from existing models

320 (Kreuzer et al. 1997, Czub and McLachlan 2004b), in order to allow a comparison of the

321 results. The application of the steady-state solution $($ eqs. 12, 13) for the mother before the

322 birth of her child avoids the need to chose an appropriate initial mass $m_{0}$ for the first

323 generation. The $95 \%$-steady-state is reached for latest $\mathrm{t}=18$ years for all chemicals with

324 the default parameterization.

325

326 The total daily uptake $I\left[\mathrm{mg} \mathrm{d}^{-1}\right]$ was calculated as the sum of uptake via diet $i_{D}[\mathrm{mg} / \mathrm{d}]$

327 and inhalation of air:

328

329

$I=i_{D}+F_{A} \times C_{A} \quad\left[\frac{m g}{d}\right]$

331 For the breast-fed baby, $i_{D}$ is 0 .

332

333 Outflux of lipids was assumed to be $10 \%$ of lipids in the diet. With $70 \mathrm{~g} \mathrm{~d}^{-1}$ as average

334 lipid ingestion, $0.007 \mathrm{~kg} \mathrm{~d}^{-1}$ outflux of lipids results. For the baby, $0.0045 \mathrm{~kg} \mathrm{~d}^{-1}(1 / 10$ of 335 influx of lipids with milk) was used. Table 1 lists the input data chosen as default for the 336 model and used in the following simulations. 
338 To calculate concentrations in the body of the child during the simulation period, the

339 respective bodyweight was used, to account for growth effects. The bodyweight of the

340 child with age (in years) was approximated by a second-order polynom fitted to growth

341 data for girls in Germany (Hesse et al. 1997) (eq. 29)

342

$343 \quad b w=-0.053 \times a g e^{2}+3.76 \times a g e+3.54$

$\left(n=36, R^{2}=0.98\right)$

344

$345<$ Table 1>

346 


\section{$347 \quad 3$ Results}

\section{$349 \quad 3.1$ Example Simulation TCDD}

350 To illustrate the general behaviour of the model, an example simulation with 2,3,7,8-

351 tetrachlordibenzo-p-dioxin (TCDD) was performed. TCDD is a highly toxic, persistent

352 lipophilic $\left(\log K_{O W} 6.76\right)$ and semivolatile $\left(K_{A W} 0.0015\right)$ compound (Rippen 1991). The

353 concentration of TCDD in air was set to $4 \mathrm{fg} \mathrm{m}^{-3}$ (background concentration in Southern

354 Germany, McLachlan 1992). Ingestion of TCDD by the mother with diet was $25 \mathrm{pg} \mathrm{d}^{-1}$

355 (Kreuzer et al. 1997). Figure 2 shows the simulated concentration of TCDD in lipids for

356 mother and child over a three-years period. The starting concentration of the mother [3.6

$357 \mathrm{ng} \mathrm{kg}{ }^{-1}$ lipid] is the steady-state concentration (eq. 13). For $\mathrm{t}>0$, the matrix solution was

358 applied. For $\mathrm{t}>0$, the concentration of TCDD in mother decreases exponentially and falls

359 to $63 \%$ of the initial concentration after $1 / 2$ year and to $42 \%$ after 1 year of nursing. The

360 initial concentration in the infant $\left[3.6 \mathrm{ng} \mathrm{kg}^{-1}\right.$ lipid] is in equilibrium to mother. It steeply

361 increases to $12.3 \mathrm{ng} \mathrm{kg}^{-1}$ lipids after $1 / 2$ year. Hereafter, it falls, due to depletion of the

362 mother's body burden and growth dilution, to $8.8 \mathrm{ng} \mathrm{kg}^{-1}$ lipids after 1 year and to $1.73 \mathrm{ng}$

$363 \mathrm{~kg}^{-1}$ lipid after 3 years (of course, 3 years nursing is rare). The concentration in lipids of

364 milk is identical to that in lipids of the mother body and was not plotted. During the

365 period of nursing, the loss of TCDD from mother with milk is higher than the daily

366 intake, which is the reason for the depletion of TCDD from the body of the mother.

367 Figure 3 shows the ratio of the TCDD-dose taken up by the infant (per kg bw) divided by

368 the dose taken up by the mother $\left(25 \mathrm{pg} \mathrm{d}^{-1}=0.42 \mathrm{pg} \mathrm{kg}^{-1} \mathrm{bw} \mathrm{d}^{-1}\right)$. The ratio is initially 110

369 and falls later to $45(\mathrm{t}=1 / 2 \mathrm{a}), 22(\mathrm{t}=1 \mathrm{a})$ and $4.5(\mathrm{t}=3 \mathrm{a})$. The dose ratio is much higher than 
370 the concentration ratio (Figure 2). Uptake of TCDD with air is neither for mother

371 (inhalation $11 \mathrm{~m} 3$ per day, uptake $44 \mathrm{fg}$ TCDD per day) nor infant (inhalation $4.5 \mathrm{~m} 3$ per

372 day, uptake $18 \mathrm{fg}$ TCDD per day) of relevance. The maximum concentration ratio child

373 to mother is reached after $t=1 / 2 a$. The concentration in the child is maximally 3.4 times

374 that in mother before birth and falls to 2.5 times $(t=1 \mathrm{a})$ and to 0.48 times $(\mathrm{t}=3 \mathrm{a})$, due to

375 rapid elimination and growth dilution. The calculated elimination half-time ( $\ln 2$ divide

376 by rate constant k) of TCDD from the body is 4.6 years for the mother before birth, 0.6

377 years for the nursing mother and only 0.34 years for the infant.

378 These simulation results can be confronted to empirical data (Kreuzer et al. 1997, Filser

379 et al. 1997). Measured concentrations of TCDD in lipids of adipose tissue and blood for

380 adults in Germany early 1990ies range from $<0.1 \mathrm{ng} \mathrm{kg}^{-1}$ lipid to $16 \mathrm{ng} \mathrm{kg}^{-1}$ lipids, with

381 an average background level of $3 \mathrm{ng} \mathrm{kg}^{-1}$ lipids (Filser et al. 1997). Concentrations in

382 breast milk vary between 1 and $3.9 \mathrm{ng} \mathrm{kg}^{-1}$ lipids, decreasing during the period of

383 nursing, with an average of about $2 \mathrm{ng} \mathrm{kg}^{-1}$ lipids. TCDD-concentrations in stillborn

384 range from of 1.3-2.1 ng/kg lipids. Concentrations of TCDD in lipids of adipose tissue,

385 faeces and blood of infants did not differ much and ranged from $<0.2$ to $7.3 \mathrm{ng} \mathrm{kg}^{-1}$ lipids.

386 TCDD levels in adipose tissue of 20 breast-fed infants aged between 0 and 44 weeks

387 ranged from 0.16 to $4.1 \mathrm{ng} \mathrm{kg}^{-1}$ tissue and were higher than that of non-breast-fed

388 children (0.16-0.76 $\mathrm{n} \mathrm{kg}^{-1}$ lipids) (Kreuzer et al. 1997). Predicted half-life of TCDD in

389 infants was short ( 0.42 years), and increased to about 10 years for adults between 40 and

39060 years of age. These results are throughout close to the outcome of the simulations with

391 the mother-child model, without any conflicting results.

$392<$ Figure $2><$ Figure $3>$ 


\section{Discussion}

\subsection{Comparison of Regression and Mother-Child Model}

396 The regression of Travis et al. (1988) uses only one physico-chemical parameter, the

$397 K_{O W}$, while the mother-child model requires $K_{O W}$ and $K_{A W}$. The bioaccumulation factors

398 (BAF), related to concentration in lipids, derived from model and regression were

399 compared. The concentration in air was set to 0 . The steady-state BAF of mother at birth

400 of the child $(\mathrm{t}=0)$ and the BAF milk after $\mathrm{t}=1 / 2$ year were plotted in Figure 4 . The BAF for

401 mother and milk are practically identical, except for very hydrophilic compounds (the

402 relation to lipids gives artificially higher concentrations for milk if compounds do not

403 partition into lipids). The model BAF differ more than two orders of amount with low

$404\left(10^{-9}\right)$ or high $(0.1) K_{A W}$ except for high $\log K_{O W}$, because volatile compounds are rapidly

405 lost from the body via exhalation. Within its regression range ( $\log K_{O W} 1.32$ to 6.50$)$, the

406 regression gives similar results as the model with high $K_{A W}$, probably because the less

407 lipophilic compounds in the training set of the regression were all solvents with high $K_{A W}$

408 (Table 2). With increasing lipophilicity, the BAF predicted by the mother-child model

409 reach a plateau (mother at $\mathrm{t}=0$ : $\mathrm{BAF}$ is $143\left[\mathrm{~d} \mathrm{~kg}^{-1}\right.$ lipid], milk at $\mathrm{t}=0.5$ years: $\mathrm{BAF}$ is 90

$410\left[\mathrm{~d} \mathrm{~kg}^{-1}\right.$ lipid]), while the BAF derived by the regression increase unlimited with $K_{O W}$. This

411 is unrealistic, except for short time-periods, as the loss of super-lipophilic compounds via

412 milk would be several orders of amount higher than the daily intake. The daily intake (1

$\left.413 \mathrm{mg} \mathrm{d}^{-1}\right)$ is balanced at a BAF milk (4.5\% lipids) of $22\left[\mathrm{~d} \mathrm{~kg}^{-1}\right.$ lipid]. The regression gives

414 a BAF $=22\left[\mathrm{~d} \mathrm{~kg}^{-1}\right.$ lipid] with $\log K_{O W}=4.7$, but higher BAF for all $\log K_{O W}$ above that

415 value. Contrary, the steady-state $(t=\infty)$ BAF milk predicted by the mother-child model for 
416 compounds with $\log K_{O W}>4.7$ is constant at $19\left[\mathrm{~d} \mathrm{~kg}^{-1}\right.$ lipid]. In the initial period of

417 nursing, the BAF milk is above steady-state, therefore, mother is depleted from POPs by

418 nursing (Fig. 2).

419

$420<$ Figure 4>

421

422

\subsection{Uptake via inhalation compared to uptake via food}

424 The impact of exhalation on BAF of hydrophilic to medium lipophilic compounds (log

$\left.425 \mathrm{~K}_{\mathrm{OW}}<5\right)$ is evident from Figure 4: fugitive compounds with high $\mathrm{K}_{\mathrm{AW}}$ show much lower

426 bioaccumulation, due to this process. On the other hand, the $\mathrm{K}_{\mathrm{Aw}}$ may also impact the

427 uptake by inhalation. Basically, this uptake is calculated from the product of

428 concentration in air and inhalation (eq. 28). Under certain conditions, such as ubiquitous

429 background distribution of persistent compounds, we may assume that the concentrations

430 in diet and air are near phase equilibrium. Using the formalism of section 2.1 , the

431 equilibrium ratio $K_{D A}\left[\mathrm{~m}^{3} \mathrm{~kg}^{-1}\right]$ between concentration in $\operatorname{diet} C_{D}\left[\mathrm{mg} \mathrm{kg}^{-1}\right]$ and in air $C_{A}$ $432\left[\mathrm{mg} \mathrm{L}^{-1}\right]$ is

433

$434 \frac{C_{D}}{C_{A}}=K_{D A}=\frac{W_{D}+L_{D} \times K_{O W}}{K_{A W}} \quad\left[\frac{L}{k g}\right]$

436 where $W_{D}$ is the water content $\left[\mathrm{kg} \mathrm{kg}^{-1}\right]$ and $L_{D}$ is the lipid content $\left[\mathrm{kg} \mathrm{kg}^{-1}\right]$ of the diet. 437

438 The relation between the input data $i_{D}$ (uptake of chemical with diet, $\mathrm{mg} \mathrm{d}^{-1}$ ) and $C_{D}$ is 
$440 \quad i_{D}=C_{D} \times F_{D}$

441

442 where $F_{D}$ is the daily dietary consumption $\left[\mathrm{kg} \mathrm{d}^{-1}\right]$. Thus, the equilibrium concentration in 443 air $C_{A, e q}\left[\mathrm{mg} \mathrm{L}^{-1}\right]$ is

444

$445 \quad C_{A, e q}=\frac{i_{D}}{K_{D A} \times F_{D}}$

447 The dose via inhalation $i_{A}\left[\mathrm{mg} \mathrm{d}^{-1}\right]$ is subsequently

448

$449 i_{A}=F_{A} \times C_{A, e q}$

451 where $F_{A}$ is the inhalation of air [mother $11 \mathrm{~m}^{3} \mathrm{~d}^{-1}$ and child $4.5 \mathrm{~m}^{3} \mathrm{~d}^{-1}$ ].

453 A typical diet of an adult Danish female $\left(F_{D}\right)$ contains $60 \mathrm{~g}$ lipids and $2 \mathrm{~L}$ water, hereof

454 1.4 L drinking water. Using these numbers, the ratio of uptake via air to uptake via diet, 455 assuming phase equilibrium between air and food (including water), was calculated.

457 Figure 5 shows that the relevance of inhalation as uptake pathway for chemicals into the 458 human body depends much on the value of the partition coefficient air to water $K_{A W}$. For 459 non-volatile compounds (low $K_{A W}, 10^{-6} \mathrm{~L} \mathrm{~L}^{-1}$ ), inhalation is not relevant at all. With very 460 low $K_{A W}\left(10^{-9} \mathrm{~L} \mathrm{~L}^{-1}\right)$, the ratio of uptake with inhalation versus uptake with diet is never 
461 above $1: 100000$ (not shown). On the other hand, inhalation is the dominant way of

462 entry into the body for volatile compounds (high $K_{A W}, 0.1 \mathrm{~L} \mathrm{~L}^{-1}$ ) with up to $\log K_{O W} 4$.

463 With moderate $K_{A W}\left(10^{-3} \mathrm{~L} \mathrm{~L}^{-1}\right.$ in Fig. 5), the relative importance of inhalation for the

464 body burden decreases, but it is still higher than uptake by diet for the less lipophilic

465 compounds $\left(\log K_{O W} \leq 2\right)$. For lipophilic compounds $\left(\log K_{O W}>5\right)$, which have the

466 highest bioaccumulation, uptake by inhalation is generally not of much relevance.

467 Compared to the mother, uptake via inhalation has similar (hydrophilic compounds) or

468 lower importance (lipophilic compounds) for the child.

469

470 Note that these calculations were done for the rare case of near-equilibrium conditions. In

471 real life, many individuals live in urban centers, while the agricultural production is in

472 remote rural areas. It may be expected that the air pollution is higher in the cities, in

473 particular when additional indoor sources of pollutants are present. Furthermore,

474 lipophilic compounds may be strongly adsorbed to particles, which are inhaled

475 simultaneously with air. Thus, these conclusions are surely not of general validity, and

476 the relative importance of inhalation for the uptake of pollutants may be higher in real life

477 than expected from the calculations displayed in Fig. 5.

478

$479<$ Figure 5 $>$

480

$481 \quad 4.3$ Validation Against Empirical Data

482 To derive their regressions for bioaccumulation in adipose tissue and breast milk, Travis

483 et al. (1988) collected twelve bioaccumulation factors (BAF) for human adipose tissue 
484 and six BAF for breast milk from literature and pharmacokinetic models. The model was

485 tested against these data. Additionally, BAF for TCDD were calculated from data in

486 Kreuzer et al. (1997). The concentrations are related to lipid content. Log $K_{O W}$-values

487 given in the original reference (Travis et al. 1988) were used, except for TCDD (Rippen

488 1991) (Table 2). One compound, pentachlorophenol, had to be excluded from the analysis

489 because it is not a neutral compound but a weak acid (Rippen 1990). The uptake of weak

490 electrolytes into living cells follows principles which are not covered by the model

491 (Trapp 2004).

492

493 <Table 2>

494

495 In order to reproduce the experimental conditions under which empirical BAF were

496 derived, concentration in air was set to zero. Figure 6 shows the measured BAF for

497 human adipose tissue of the 12 organic compounds, the results from the regression by

498 Travis et al. (1988) and the model outcome for mother before birth at steady-state. The

499 measured BAF range from 0.013 (TCE) to 724 (DDE) and are lowest for the volatile

500 compounds with low $\log K_{O W}$. Naturally, the regression predicts this range, and its results

501 are generally less than factor 5 from the measurements, except for TCDD (over-predicted

502 factor 21), which is out of the regression range. The model simulations, too, are close to

503 the measured data. The results differ maximally factor 7 (dieldrin). The averaged ratio

504 between predicted and measured BAF is 1.54 for the regression $(3.15$, including TCDD)

505 and 2.0 for the model (including TCDD). 
507 Figure 7 shows the measured BAF for human milk of seven organic compounds. The

508 measured BAF range from 43 (dieldrin) to 1660 (PCB). The regression results are quite

509 close to the measured BAF, except for TCDD. To derive the BAF, averaged values from

510 milk samples in the period between birth and up to 18 month after birth have been used

511 (Rogan et al. 1986). Therefore, the measured BAF were compared to the model result at

512 birth ( $\mathrm{t}=0)$ and for $\mathrm{t}=1$ year. The calculated BAF milk are higher for $\mathrm{t}=0$ and do not vary

513 much, as all compounds are lipophilic with $\log K_{O W}>4.7$. The predicted BAF are

514 somewhat too low, except for dieldrin and TCDD. The largest deviation is seen for PCB,

515 which is not a single compound but a mix of 209 congeners. The averaged ratio between

516 regression result and measured BAF is 2.02 (1.09 without TCDD). The ratio between

517 model prediction and measurements is 0.99 ( 0.87 without TCDD) for $\mathrm{t}=0$ and $0.42(0.37$

518 without TCDD) for $\mathrm{t}=1$ year.

$520<$ Figure 6 $><$ Figure $7>$

521

\section{$522 \quad 4.4$ Comment on Nursing}

523 The question is often raised whether nursing may have an adverse impact on the health of

524 the child (BgVV 2000). While the high dose of POPs (here: TCDD) that the infant

525 receives with breast milk suggests so, the moderate increase of infant body concentration

526 gives less reasons to be concerned. There is evidence that after a few life-years, the

527 difference between breast-fed and formula-fed infants in their body-burden with POPs,

528 such as TCDD, vanishes (Kreuzer et al. 1997). If the mother nurses more than one child

529 without longer periods in between, the model predicts lower body-burdens for the later 
530 children, i.e., for the second child after one year nursing, the body concentration is about

531 the same as in the mother, if she never had breast-fed. Empirical studies confirm that the

532 first born child is at higher risk to be exposed to POPs that have accumulated in mother

533 and are transferred via mother milk (Tanabe and Kunisue 2007), and that levels of POPs

534 decrease during lactation (Harris et al. 2001). An argument pro nursing may also be that

535 the mother reduces her POP pool (Schecter et al. 1996). Metabolism in the body of the

536 mother reduces the dose transferred to the nursing infant. With metabolism half-times

537 below 14 days, the model predicts that the dose the nursing infant receives is always

538 below the dose for the mother. According to the model, the mother has a "filter effect" for

539 less lipophilic and volatile compounds: for those, the dose for the infant via breast milk is

540 lower than the dose mother takes up (per kg bodyweight) (Figure 4).

\section{$542 \quad$ 4.5 Limitations and Application Range of the New Model}

543 The new mother-child model is, due to the underlying equations for phase equilibrium,

544 not valid for inorganic (Wuenschmann et al. 2008) and electrolytic organic compounds

545 (Trapp 2004, Trapp and Horobin 2005). The assumption of phase equilibrium within the

546 body for neutral lipophilic organic compounds is supported by the results of Kreuzer et

547 al. (1997), who found comparable levels of TCDD in lipids of adipose tissue, feces,

548 blood, liver, breast milk and new-borns. Deviations from equilibrium could in particular

549 occur for compounds with rapid metabolism. However, for those the model predicts low

550 transfer into infants anyhow, thus, a "false alarm" due to over-prediction would not occur,

551 if accurate metabolism rate constants are at hand. 
553 The new mother-child model is more complex than the regression of Travis et al. (1988),

554 but still the structure is relatively easy, and the analytical solution of the differential

555 equations keeps the calculations compact and robust. The model requires five chemical

556 input parameters $\left(i_{D}, K_{O W}, C_{A}, K_{A W}\right.$ and $\left.k_{d e g}\right)$. It may be more troublesome to acquire these

557 data, but the differences in the accumulation behavior of persistent and reactive

558 compounds can be considered, and uptake via diet and inhalation can be calculated

559 simultaneously or separately. Therefore, results from diet studies can be used as input

560 data, and bioaccumulation factors as defined by Travis et al. (1988) can be calculated,

561 using $i_{D}=1 \mathrm{mg} \mathrm{d}^{-1}$ and $C_{A}=0$. The regression necessarily will fail if uptake from air plays

562 a major role.

563

564 Another advantage of the deterministic approach, compared to empirical relations, is that

565 the relevant processes behind the BAF can be identified. The variation of physiological

566 parameters (for the human body) allows to determine the influence of age, diet,

567 bodyweight, growth, metabolism etc. Furthermore, the regression violates the mass

568 balance for more lipophilic compounds with high $\log K_{O W}$ and gives unrealistically high

569 BAF, as was shown before.

570

571 In comparison to more sophisticated models for bioaccumulation (Kreuzer et al. 1997,

572 Molen et al. 1996, Maruyama et al. 2003), the new mother-child model is more compact

573 and more variable (i.e., it does not require the measurement of any chemical-specific

574 data, besides the minimum data set, and it needs no calibration steps). Compared to the

575 human bioaccumulation model ACC (Czub and McLachlan 2004b), which calculates the 
576 body concentration of a single human over the whole life-time, the mother-child model is

577 less complex and more flexible, due to the analytical solution. If, for the purpose of risk

578 assessment, only the dose for the infant is required, the differential equation system is

579 decoupled, and the solution for the breast-feeding mother alone can be solved (eq. 11). 580

581 The development of the new mother-child model was driven by the need to predict the 582 exposure of nursing children within the framework of chemical risk assessment and/or 583 risk assessment of polluted sites. Model systems for these purposes exist (EC 1996,

584 Rikken et al. 2001, Kulhanek et al. 2004) but none of them considers nursing infants (in 585 fact, children are not considered at all in most of them). The new model could be added 586 with small effort to existing exposure assessment tools, in order to fill this gap.

588 Model availability

589 The new mother-child model is available as unprotected excel-spreadsheet version from 590 the first author. Please mail to stt@er.dtu.dk.

\section{Acknowledgements}

593 This work received financial support from the European Union 6th Framework

594 Programme of Research, Thematic Priority 6 (Global change and ecosystems), contract 595 number GOCE-CT-2007-036976, project 2-FUN, and contract number GOCE 037017, 596 project OSIRIS. Support for this work was also provided through a PhD grant of the 597 University of Copenhagen and the Research School of Environmental Chemistry and 598 Ecotoxicology (RECETO) for Charlotte N. Legind. 


\section{References}

$600 \mathrm{BgVV}$ (Bundesinstitut für gesundheitlichen Verbraucherschutz und Veterinärmedizin), Deutschland - Aufbau der Frauenmilch- und Dioxin-Humandatenbank am BgVV. http://www.bfr.bund.de/cd/432 accessed 12 March 2006.

CEHAPE Children's Environment and Health Action Plan for Europe, 2004. Fourth Ministerial Conference on Environment and Health, Budapest, Hungary, 23-25 June 2004. Working paper. http://www.euro.who.int/document/che/edoc07.pdf accessed 4 July 2007.

Czub, G., McLachlan, M.S., 2004a. Bioaccumulation potential of persistent organic chemicals in humans. Environ. Sci. Technol. 38, 2406-2412.

Czub, G., McLachlan, M.S., 2004b. A food chain model to predict the levels of lipophilic organic contaminants in humans. Environ. Toxicol. Chem. 23, 2356-2366.

Dahl, P., Lindström, G., Wiberg, K., Rappe, C., 1995. Absorption of polychlorinated biphenyls, dibenzo-p-dioxins and dibenzofurans by breast-fed infants. Chemosphere 30, 2297-2306.

Deurenberg, P., Weststrate, J.A., Seidell, J.C., 1991. Body mass index as a measure of body fatness: age- and sex- specific prediction formulas. British Journal of Nutrition 65, 105-114.

EC (European Commission), 1996. EUSES, the European Union System for the Evaluation of Substances. National Institute of Public Health and the Environment (RIVM), The Netherlands. Available from the European Chemicals Bureau (EC/DG XI), Ispra, Italy.

EC (European Commission), 2003. Technical Guidance Document on Risk Assessment in support of Commission Directive 93/67/EEC on Risk Assessment for new notified substances, Commission Regulation (EC) No 1488/94 on Risk Assessment for existing substances, and Directive 98/8/EC of the European Parliament and of the Council concerning the placing of biocidal products on the market. Available at http://ecb.jrc.it/documents/

Filser, J.G., Baur, C., Csanády, G., Kessler, W., Kreuzer, P.E., 1997. Toxicokinetic modeling as a tool for risk estimation: 2,3,7,8-Tetrachlorodibenzo-p-dioxin. Int. J. Toxicol. 16, 433-448.

Harris, C.A., Woolridge, M.W., Hay, A.W.M., 2001. Factors affecting the transfer of organochlorine pesticide residues to breastmilk. Chemosphere 43, 243-256. 
Harrison, K., 2001. Too close to home: Dioxin contamination of breast milk and political agenda. Policy Science 34, 35-62.

Hesse, V., Jaeger, U., Vogel, H., Kromeyer, K., Zellner, K., Bernhardt, I. et al., 1997. Wachstumsdaten deutscher Kinder von Geburt bis zu 18 Jahren. Sozialpädiatrie $19,20-22$.

Kreuzer, P.E., Csanády, G., Baur, C., Kessler, W., Päpke, O., Greim, H., Filser, J.G., 1997. 2,3,7,8-Tetrachlorodibenzo- p-dioxin (TCDD) and congeners in infants. A toxicokinetic model of human lifetime body burden by TCDD with special emphasis on its uptake by nutrition. Arch. Toxicol. 71, 383-400.

Kulhanek, A., Trapp, S., Sismilich, M., Janků, J., Zimová, M., 2005. Crop-specific human exposure assessment for polycyclic aromatic hydrocarbons in Czech soils. Sci. Tot. Environ. 339, 71-80.

Layton, D,W., 1993. Metabolically consistent breathing rates for use in dose assessments. Health Physics 64, 23-26.

Maruyama, W., Yoshida, K., Tanaka, T., Nakanishi, J., 2003. Simulation of dioxin accumulation in human tissues and analysis of reproductive risk. Chemosphere 53, 301-313.

McLachlan, M.S., 1992. Das Verhalten hydrophober chlororganischer Verbindungen in laktierenden Rindern [doctoral thesis]. University of Bayreuth, Germany.

Van Der Molen, G.W., Kooijman, S.A.L.M., Slob, W., 1996. A generic toxicokinetic model for persistent lipophilic compounds in humans: an application to TCDD. Fundamental and Applied Toxicology 31, 83-94.

Nazaroff, W.N., Alvarez-Cohen, L., 2001. Environmental Engineering Science, John Wiley \& Sons, New York, pg. 624-625.

Raab, U., Schwegler, U., Preiss, U., Albrecht, M., Fromme, H., 2007. Bavarian breast milk survey - Pilot study and future developments. Int. J. Hyg. Environ. Health 210, 341-344.

Rikken, M.G.J., Lijzen, J.P.A., Cornelese, A.A., 2001. Evaluation of model concepts on human exposure. Proposals for updating the most relevant exposure routes of CSOIL. RIVM report 711701 022, Bilthoven, The Netherlands.

Rippen, G., 1990-2007 (permanently updated). Handbuch Umweltchemikalien, ecomed, Landsberg am Lech, D.

Rogan, W.J., Gladen, B.C., McKinney, J.D., Carreras, N., Hardy, P., Thullen, J. et al. 1986. Polychlorinated biphenyls (PCB) and dichlorophenyl dichloroethane (DDE) 
in human milk: effects of maternal factors and previous lactation. Am. J. Public Health 76, 172-177.

Schade, G., Heinzow, B., 1998. Organochlorine pesticides and polychlorinated bipheyls in human milk of mothers living in northern Germany: Current extent of contamination, time trend from 1986 to 1997 and factors that influence the levels of contamination. Sci. Tot. Environ. 215, 31-39.

Schecter, A., Päpke, O., Lis, A., Ball, M., Ryan, J.J., Olson, J.R. et al., 1996. Decrease in milk and blood dioxin levels over two years in a mother nursing twins: Estimates of decreased maternal and increased infant dioxin body burden from nursing. Chemosphere 32, 543-549.

Shen, H., Main, K.H., Virtanen, H.E., Damggard, I.N., Haavisto, A.-M., Kaleva, M., Boisen, K.A., Schmidt, I.M., Chellakooty, M., Skakebaek, N.E., Toppari, J., Schramm, K.-W., 2007. From mother to child: Investigation of the prenatal and postnatal exposure to persistent bioaccumulating toxicants using breast milk and placenta biomonitoring. Chemosphere 67, S256-S262.

Tanabe, S., Kunisue, T., 2007. Persistent organic pollutants in human breast milk from Asian countries. Environ. Pollut. 146, 400-413.

Trapp, S., 2004. Plant uptake and transport models for neutral and ionic chemicals. Environ. Sci. \& Pollut. Res. 11, 33-39.

Trapp, S., Horobin, R.W., 2005. A predictive model for the selective accumulation of chemicals in tumor cells. Eur. Biophys. J. 34, 959-966.

Travis, C.C., Hattemer-Frey, H.A., Arms, A.A., 1988. Relationship between dietary intake of organic chemicals and their concentrations in human adipose tissue and breast milk. Arch. Environ. Contam. Toxicol. 17, 473-478.

Travis, C.C., Hattemeyer-Frey, H.A., 1991. Human exposure to dioxin. Sci. Tot. Environ. 104, 97-127.

UNEP United Nations Environmental Program, 2007. Stockholm convention on persistent organic pollutants (POPs). http://www.pops.int/ accessed 4 June 2007.

US EPA U.S. Environmental Protection Agency, 2006. Children's Environmental Health: 2006 Report. Environment, Health, and a Focus on Children. http://yosemite.epa.gov/ochp/ochpweb.nsf/content/homepage.htm accessed 4 July 2007.

Wittsiepe, J., Fürst, P., Schrey, P., Lemm, F., Kraft, M., Eberwein, G. et al., 2007. PCDD/F and dioxin-like PCB in human blood and milk from German mothers. Chemosphere 67, S286-S294. 
736 Wuenschmann, S., Fraenzle, S., Markert, B., Zechmeister, H., 2008. Input and transfer of trace metals from food via mothermilk to the child - bioindicative aspects to human health, in: Prasad, M.N.V. (Ed.), Trace Elements: Nutritional Benefits, Environmental Contamination, and Health Implications. John Wiley and Sons, New York, in press. 
741 Table 1. Default input data for the mother-child model.

\begin{tabular}{|l|l|l|l|l|}
\hline Parameter & Symbol & Value & Unit & Reference \\
\hline Mother & & & & \\
\hline Age & $t$ & 25 & $\mathrm{a}$ & Kreuzer et al. (1997) \\
\hline Body mass & $M_{H}$ & 60 & $\mathrm{~kg}$ & Maruyama et al. (2003) \\
\hline Body water fraction & $W$ & 0.71 & $\mathrm{~L} / \mathrm{kg}$ & Czub and McLachlan (2004b) \\
\hline Body lipid fraction & $\mathrm{L}$ & 0.284 & $\mathrm{~kg} / \mathrm{kg}$ & Deurenberg et al. (1991) \\
\hline Outflux of water & $F_{W}$ & 1.24 & $\mathrm{~L} \mathrm{~d}$ & Maruyama et al. (2003) \\
\hline Outflux of lipid & $F_{L}$ & 0.007 & $\mathrm{~kg} \mathrm{~d}^{-1}$ & $10 \%$ of lipids in diet \\
\hline In/exhalation of air & $F_{A}$ & 11 & $\mathrm{~m}^{3} \mathrm{~d}^{-1}$ & Layton (1993) \\
\hline Breast milk data & & & & \\
\hline Milk flux & $F_{M}$ & 1 & $\mathrm{~kg} \mathrm{~d}^{-1}$ & Kreuzer et al. (1997) \\
\hline Milk water content & $W_{M}$ & 0.87 & $\mathrm{~L} \mathrm{~kg}^{-1}$ & Czub and McLachlan (2004b) \\
\hline Milk lipid content & $L_{M}$ & 0.045 & $\mathrm{~kg} \mathrm{~kg}^{-1}$ & Kreuzer et al. (1997) \\
\hline Child & & & & \\
\hline Age & $t$ & $0-3$ & $\mathrm{a}$ & \\
\hline Body mass & $M_{b}$ & $3.5-7.25$ & $\mathrm{~kg}$ & Hesse et al. (1997) \\
\hline Body water fraction & $W$ & 0.71 & $\mathrm{~L}^{-1} \mathrm{~kg}^{-1}$ & Czub and McLachlan (2004b) \\
\hline Body lipid fraction & $L$ & 0.233 & $\mathrm{~kg}^{\prime} \mathrm{kg}^{-1}$ & Deurenberg et al. (1991) \\
\hline Outflux of water & $F_{W}$ & 0.87 & $\mathrm{~L} \mathrm{~d}^{-1}$ & water content of 1 kg milk \\
\hline Outflux of lipid & $F_{L}$ & 0.0045 & $\mathrm{~kg} \mathrm{~d}^{-1}$ & $10 \%$ of influx \\
\hline Outflux of air & $F_{A}$ & 4.5 & $\mathrm{~m}^{3} \mathrm{~d}^{-1}$ & Layton (1993) \\
\hline Other data & & & & \\
\hline Density of water & $\rho_{W}$ & 1 & $\mathrm{~kg} \mathrm{~L}^{-1}$ & \\
\hline Density of lipids & $\rho_{L}$ & 0.82 & $\mathrm{~kg} \mathrm{~L}^{-1}$ & \\
\hline Density of air & $\rho_{A}$ & $1.3 \times 10^{-3}$ & $\mathrm{~kg} \mathrm{~L}^{-1}$ & \\
\hline
\end{tabular}


743 Table 2. Names and physico-chemical data of the compounds in Travis et al. (1988).

\begin{tabular}{|c|c|c|c|}
\hline Abbreviation & Compound & $\log K_{\text {ow }}{ }^{a}$ & $K_{A W}^{b}$ \\
\hline Benzene & benzene & 2.13 & 0.23 \\
\hline $\mathrm{DDE}$ & 1,1-bis(4-chlorphenyl)-2,2-dichlorethen & 5.83 & 0.05 \\
\hline DDT & 1,1-bis(4-chlorphenyl)-2,2,2-trichlorethan & 5.76 & 0.0016 \\
\hline DCM & dichlormethane & 1.32 & 0.087 \\
\hline Dieldrin & dieldrin & 5.16 & 0.0044 \\
\hline $\mathrm{HE}$ & heptachlor epoxide & 5.40 & 0.01 \\
\hline $\mathrm{HCB}$ & hexachlorbenzene & 5.45 & 0.028 \\
\hline PCE & perchlorethene & 2.53 & 0.54 \\
\hline PCB & polychlorinated biphenyls & 6.50 & $0.001^{\mathrm{c}}$ \\
\hline TCE & trichlorethene & 2.33 & 0.35 \\
\hline $\mathrm{MC}$ & methylchloroform & 2.47 & 0.715 \\
\hline TCDD & $2,3,7,8$-tetrachlordibenzo- $p$-dioxin & $6.76^{b}$ & 0.0015 \\
\hline
\end{tabular}

744 a) Travis et al. (1988) if not given otherwise; b) Rippen (1991-2007) if not given otherwise;

745 c) estimate; PCB is a mix of 209 compounds. 
Figure Captions

Figure 1. System overview

Figure 3. Ratio of the TCDD-dose taken up by the nursing infant (per $\mathrm{kg} \mathrm{bw}$ ) to the dose taken up by the mother $\left(25 \mathrm{pg} \mathrm{d}^{-1}=0.42 \mathrm{pg} \mathrm{kg}^{-1} \mathrm{bw} \mathrm{d}^{-1}\right)$.

Figure 2. Concentrations in nursing mother and child (ng kg${ }^{-1}$ lipids) after uptake of 25 pg TCDD per day with diet by the mother.

Figure 4. Calculated bioaccumulation factor $(\mathrm{BAF})$ mother $(\mathrm{t}=0)$ and milk $(\mathrm{t}=0.5 \mathrm{a})$ with varying $\log K_{O W}$ for low $K_{A W}\left(K_{A W}=10^{-9} \mathrm{~L} \mathrm{~L}^{-1}\right)$ and high $K_{A W}\left(K_{A W}=0.1 \mathrm{~L} \mathrm{~L}^{-1}\right)$ compared to the result derived with the regression of Travis et al. (1988).

Figure 6. Bioaccumulation factors (related to lipid content) for human adipose tissue for 12 neutral organic compounds collected from literature (Lit) compared to the regression by Travis et al. (1988) and the model outcome for mother before birth at steady-state.

780

Figure 5. Calculated ratio of uptake via inhalation to uptake via diet for the assumption of phase equilibrium for mother and child $\left(\mathrm{t}=0.5\right.$ a) with varying $\log K_{O W}$ for high $K_{A W}$ $\left(K_{A W}=0.1 \mathrm{~L} \mathrm{~L} \mathrm{~L}^{-1}\right)$, moderate $K_{A W}\left(K_{A W}=0.001 \mathrm{~L} \mathrm{~L} \mathrm{~L}^{-1}\right)$ and low $K_{A W}\left(K_{A W}=10^{-6} \mathrm{~L} \mathrm{~L}^{-1}\right)$. Dotted line shows ratio 1:1.

Figure 7. Bioaccumulation factors (related to lipid content) for human milk for 7 neutral organic compounds collected from literature (Lit) compared to the regression by Travis et al. (1988) and the model outcome for $\mathrm{t}=0$ (model $\mathrm{t}=0$, at birth) and $\mathrm{t}=1$ year (model $\mathrm{t}=1)$. 


\section{MOTHER}

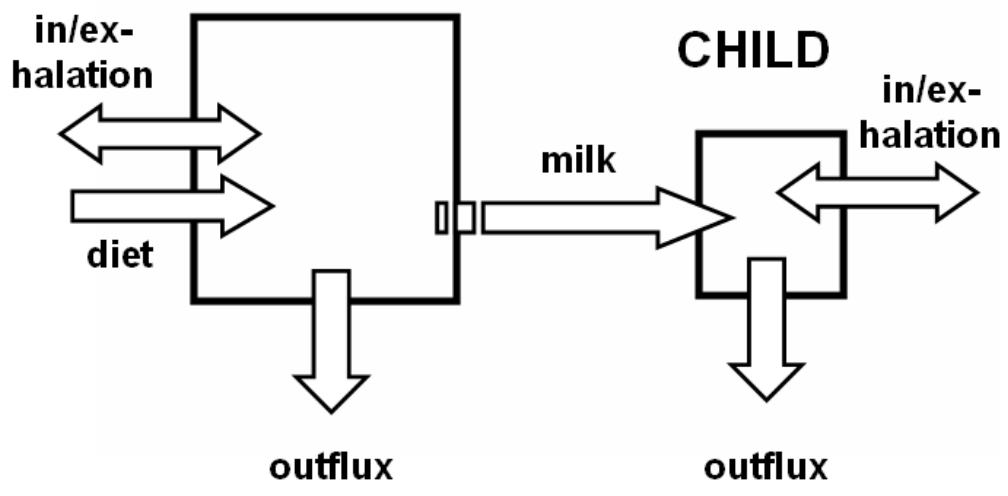

$782 \quad$ Figure 1 


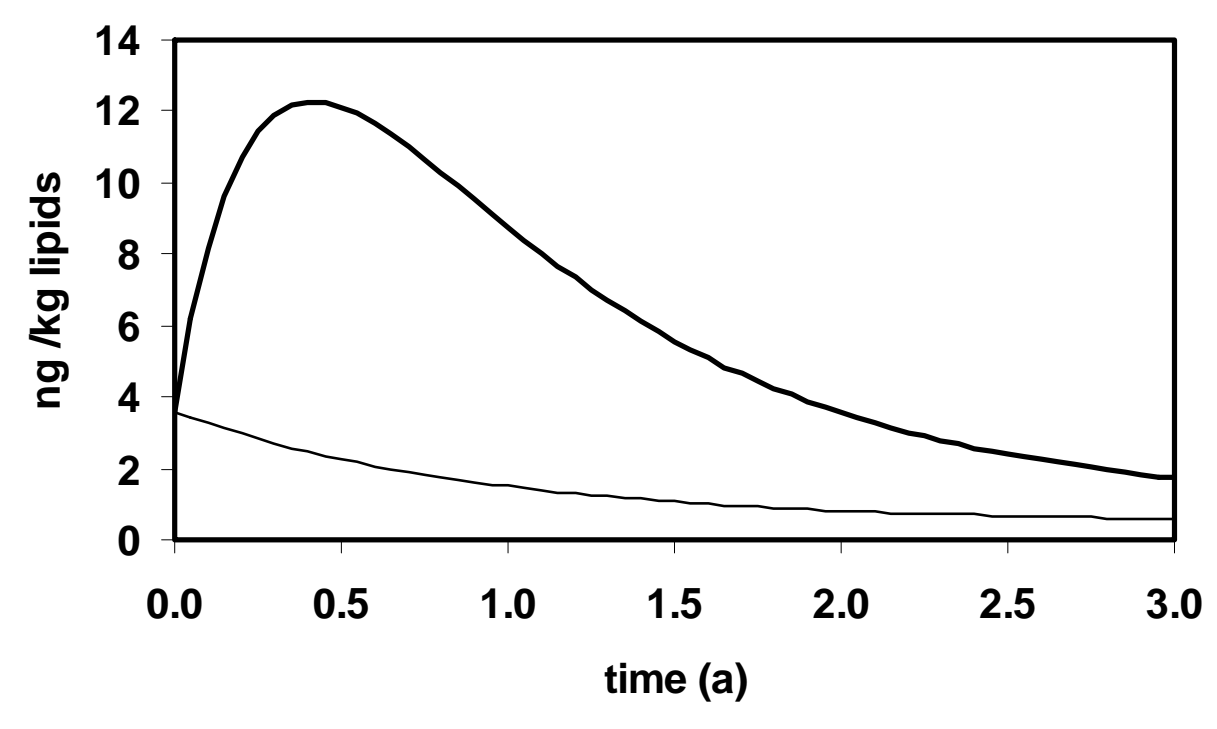

784

- Mother —Child

$785 \quad$ Figure 2 


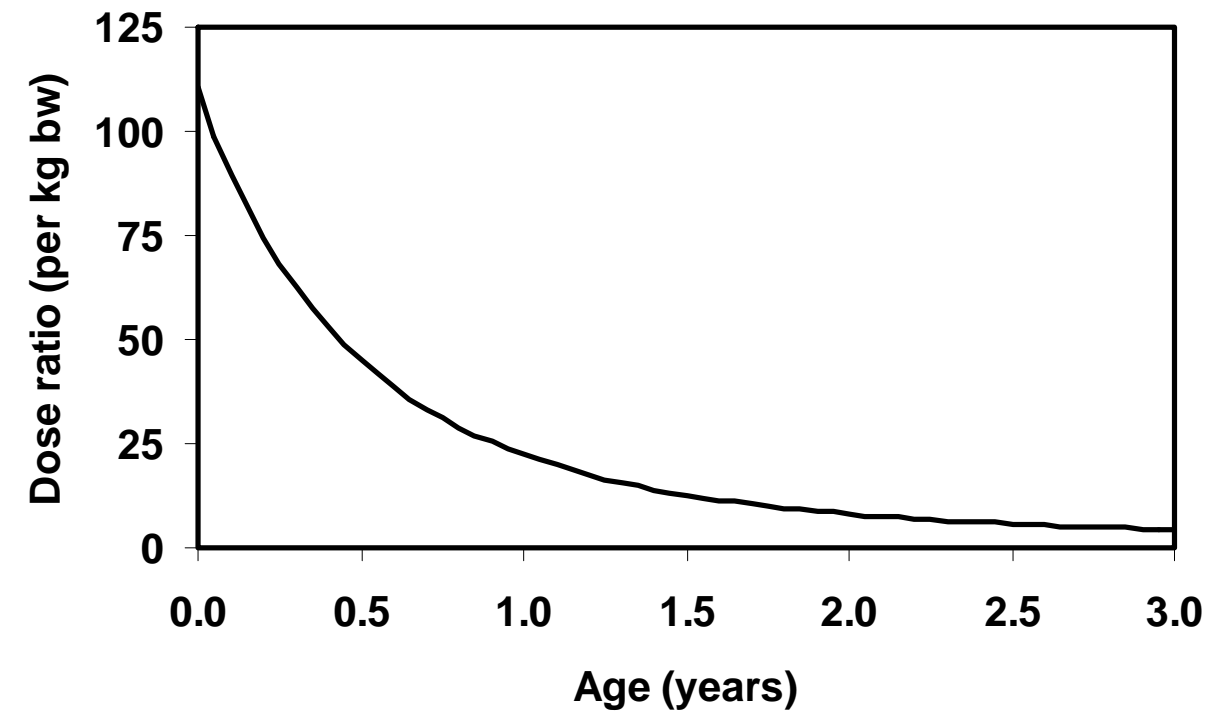

786

$787 \quad$ Figure 3 


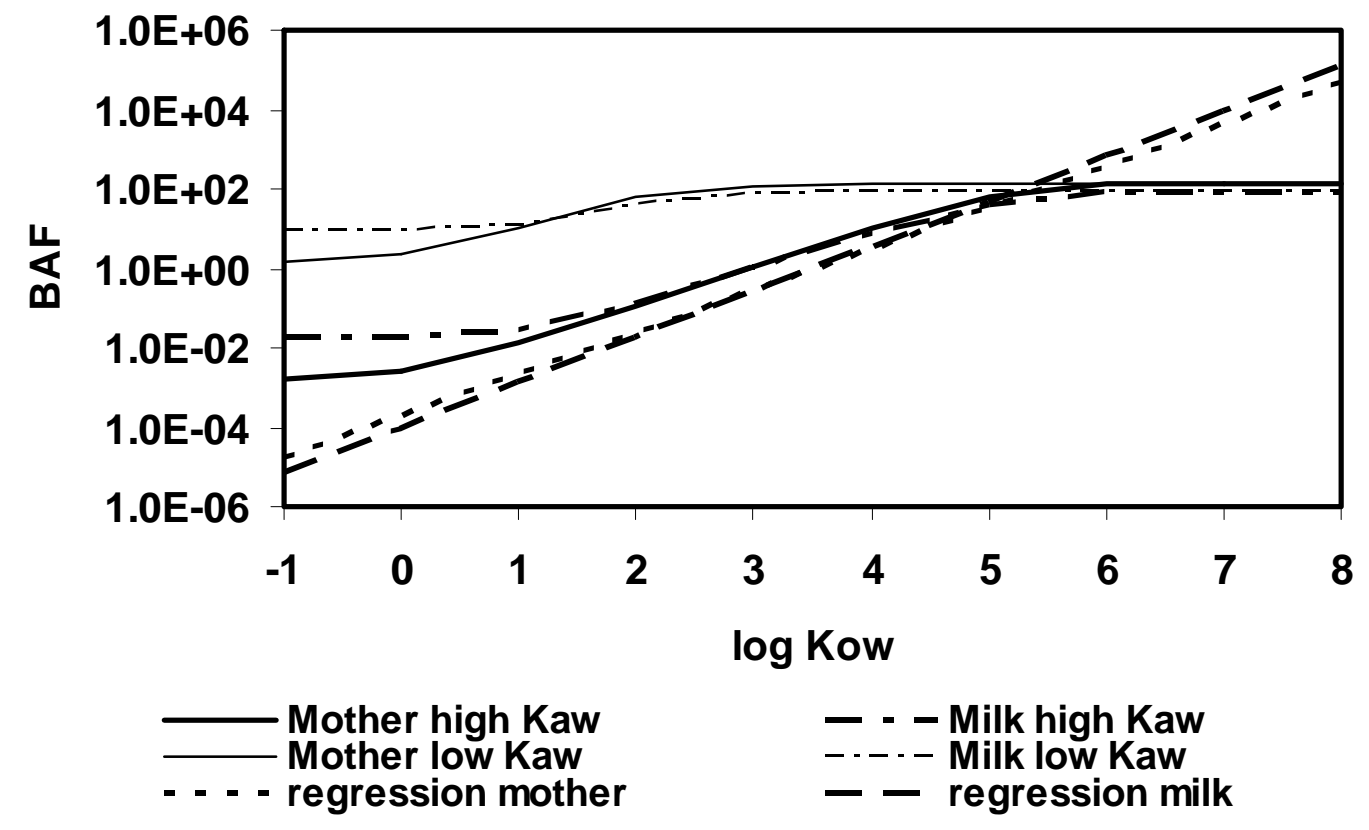

$789 \quad$ Figure 4 

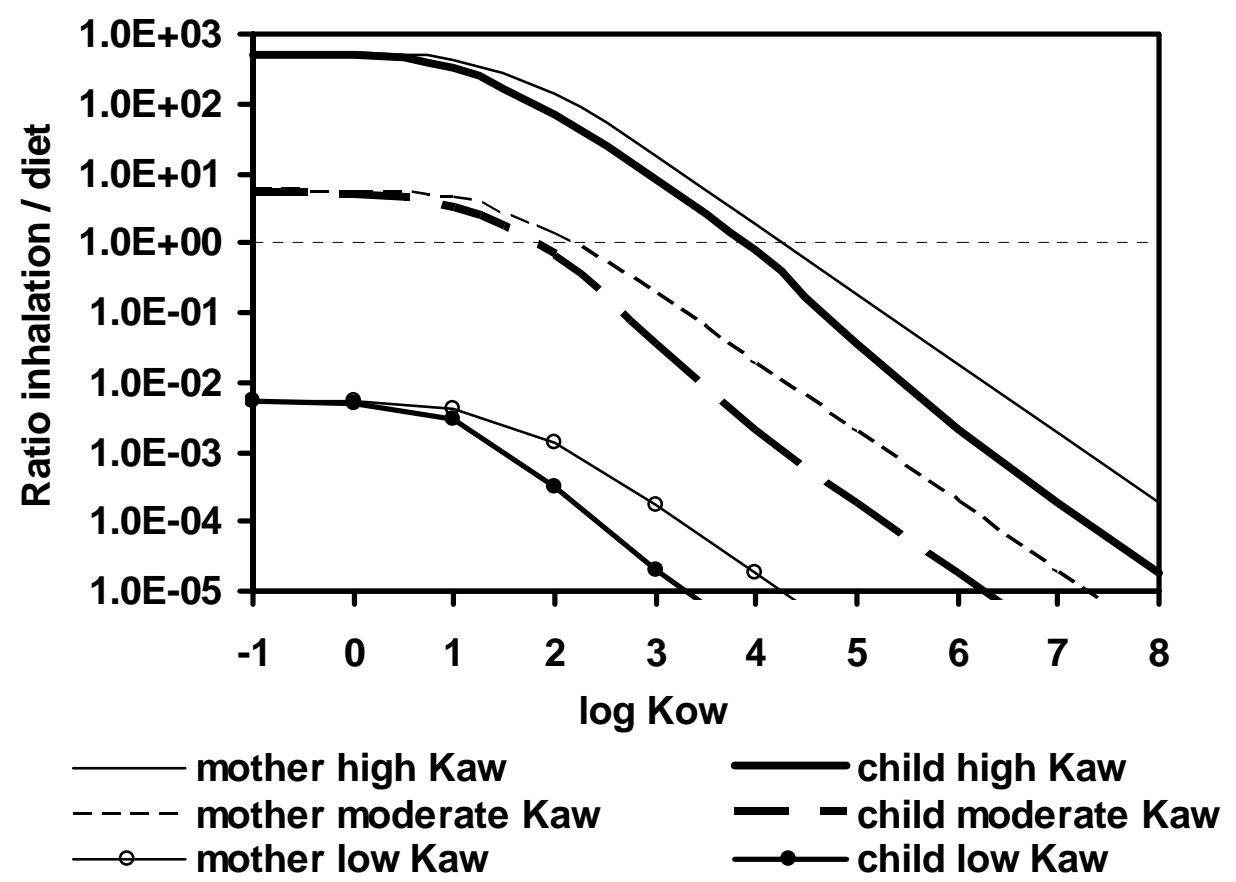

792 Figure 5 


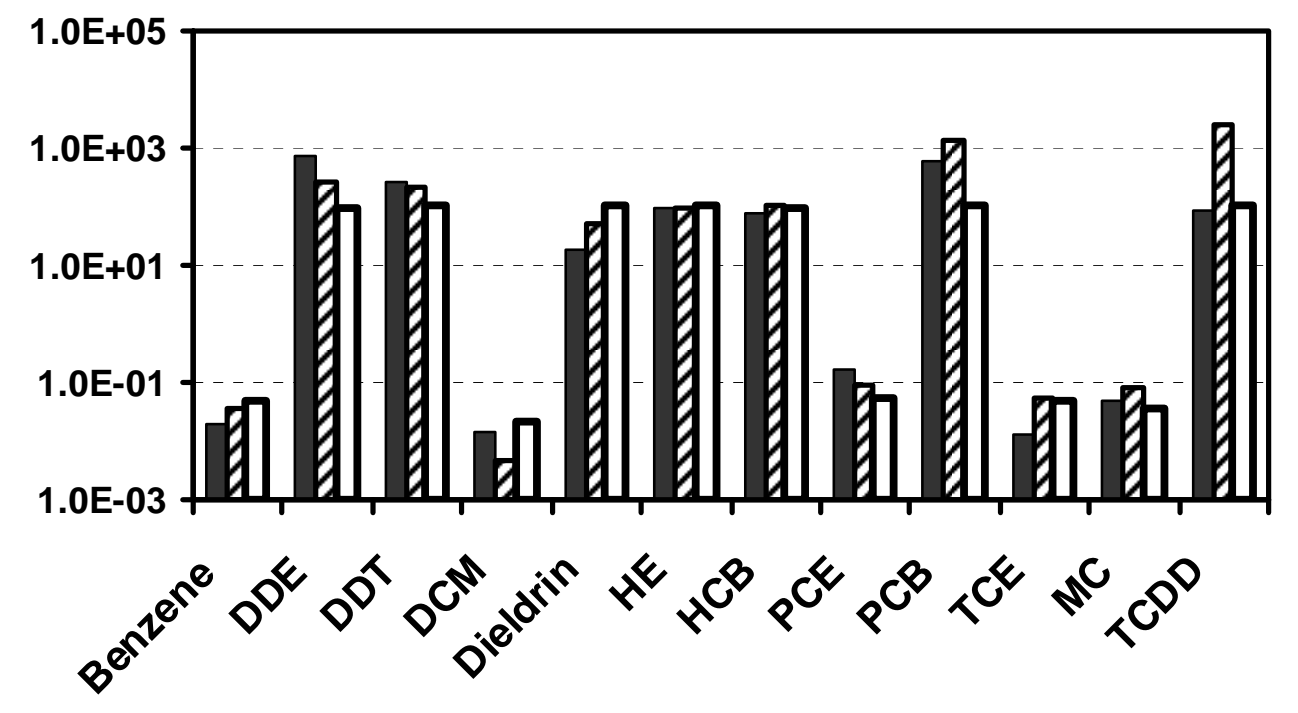

793

$\square$ Lit $\square$ regression $\square$ model mother

$794 \quad$ Figure 6 


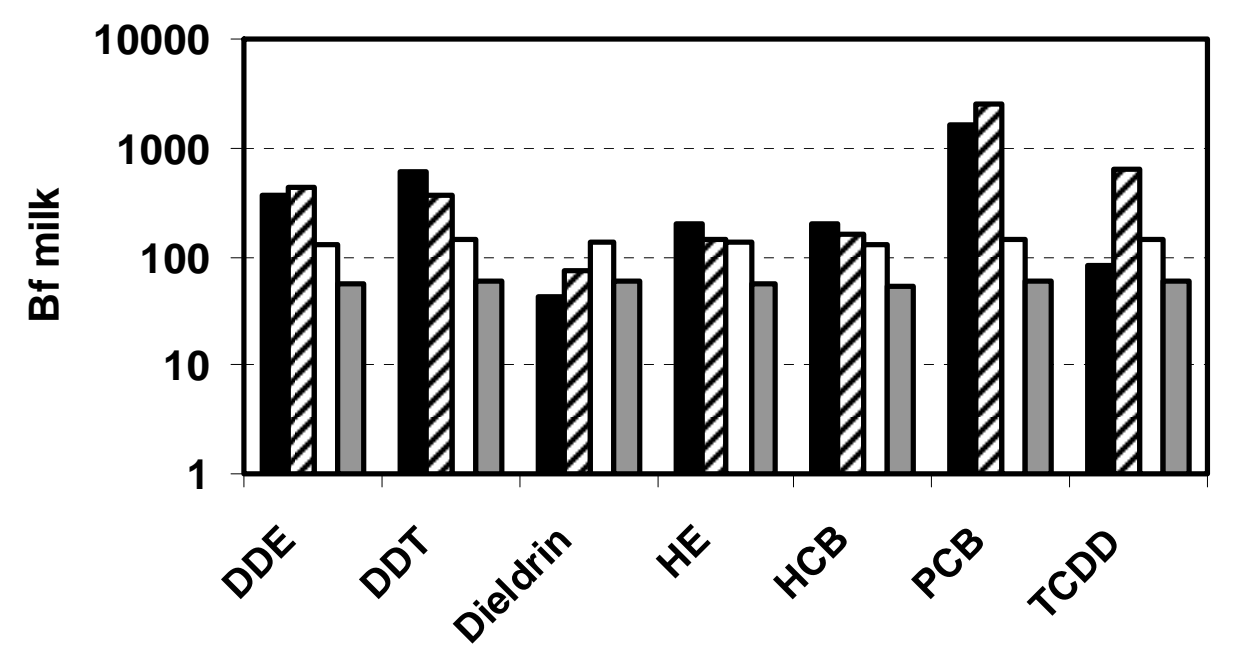

796

$\square$ Lit $\square$ regr milk $\square$ model $t=0 \square$ model $t=1$

$797 \quad$ Figure 7

798 